\title{
Prospective randomized controlled trial comparing the functional outcome of olecranon osteotomy versus triceps tongue elevation for surgical exposure of distal humerus in adults
}

\author{
Rajak $A^{1}$, Maharjan $\mathrm{R}^{2}$, Shrestha $\mathrm{BP}^{3}$, Chaudhary $\mathrm{P}^{4}$, Kalawar RPS ${ }^{5}$
}

${ }^{1}$ Asish Rajak, Lecturer; ${ }^{2}$ Rajiv Maharjan, Additional Professor; ${ }^{3}$ Bikram Prasad Shrestha, Professor; ${ }^{4}$ Pashupati Chaudhary, Professor and Head; ${ }^{5}$ Rosan PS Kalawar, Associate Professor; Department of Orthopaedics, B.P. Koirala Institute of Health Sciences, Dharan, Sunsari, Nepal.

\begin{abstract}
Background: Fractures of the distal end of the humerus are difficult to treat. The goal of treatment is to achieve a stable, painless elbow with early adequate range of motion. They are operated mainly by posterior approach among which olecranon osteotomy (bony component violation) and triceps tongue elevation (soft tissue component breach) were used in this study.

Objectives: The aim of this study was to compare olecranon osteotomy and triceps tongue elevation in terms of functional outcome (Mayo elbow performance index), rates of complications and others.

Methodology: A randomized control trial was conducted including 39 eligible adults (20 in triceps tongue elevation and 19 in olecranon osteotomy group) presenting to B.P. Koirala Institute of Health Sciences during the study period of 12 months duration. All skeletally mature adult patients with isolated traumatic closed intra-articular or distal end fracture of humerus without distal neurovascular deficit were included. Patients with polytrauma, refractures, compartment syndrome and patient not giving consent were excluded from the study. They were operated and followed up at $2,6,12$ and 24 weeks.

Results: The demographic profiles of the two groups were comparable. There was significant difference between the intraoperative time between the two groups ( $p=0.009)$. At final follow up, there were no significant differences in functional outcome and complications.

Conclusion: The approaches are comparable in terms of union, post-operative function and complications. There was increased intraoperative time in the olecranon osteotomy approach suggesting that patients who cannot tolerate longer intraoperative time may benefit from triceps tongue elevation approach.
\end{abstract}

Key words: Mayo elbow performance index; Olecranon osteotomy; Triceps tongue elevation.

DOI: https://doi.org/10.3126/jkmc.v7i4.23296

\section{INTRODUCTION}

$\mathrm{F}_{\mathrm{s}}^{\mathrm{rat}}$ ractures of the distal end of the humerus are of all fractures, and $30 \%$ of elow of treatment is to achieve a stable, painless elbow with early adequate range of motion which can be achieved with internal fixation, anatomical reduction and preservation of blood supply ${ }^{2,3}$. The debate lies in

Address for correspondence

\section{Dr. Asish Rajak}

Lecturer, Department of Orthopaedics

B.P. Koirala Institute of Health Sciences, Dharan, Sunsari, Nepal.

E-mail: asishrjk@gmail.com the surgical approach/technique, choice of implant and rehabilitation protocol and/or timing of mobilisation.

Virtually no study in Nepal has been done to compare the merits and demerits of distal humerus exposure techniques with olecranon osteotomy and triceps tongue elevation. Hence, the rationale was to compare between these, to have a better and clear evidence for choosing the surgical approach.

The objective was to compare the two approaches with respect to Mayo Elbow Performance Index (MEPI) for functional outcome and related complications. 


\section{METHODOLOGY}

The study was a prospective randomized controlled trial conducted in the Department of Orthopaedics, B.P. Koirala Institute of Health Sciences, a tertiary care hospital in Eastern Nepal, over a period of twelve months from September 2015 to August 2016. Ethical clearance was obtained from Institutional Review Committee (IRC). All skeletally mature adult patients with isolated traumatic closed intra-articular distal end fracture of humerus without distal neurovascular deficit presenting to Emergency and the outpatient department; giving written and informed consent were included in the study. Patients with re-fractures, polytrauma, fracture dislocations, pathological fracture and compromised soft tissue (example: Compartment syndrome) were excluded from the study.

On the basis of literature of Gupta $G$ et al. the sample size was calculated to be 20 in each group ${ }^{3}$. Thirty-nine patients were enrolled in the study. After randomization using computerized Excel random number generation technique: 20 fell in triceps tongue elevation group and 19 in olecranon osteotomy group. The patients were administered analgesics and limb was splinted after being received. A prior informed and written consent was taken from each patient regarding the study after explaining about the procedures, complications and possible outcomes. All cases were admitted, history was obtained and clinical examination was done with recording of distal neurovascular deficit. Diagnosis was confirmed by X-ray of the elbow on lateral and anteroposterior views. Fracture was classified according to $A O$ classification system. Intravenous Cefuroxime $1.5 \mathrm{gram}$ was administered after skin test in all cases within one hour before incision as prophylactic antibiotics. After appropriate anaesthesia, the patient was positioned in lateral decubitus position, the entire upper extremity draped free and pneumatic tourniquet applied. When operative time exceeded over one hour tourniquet was deflated and again inflated. The duration of tourniquet application was noted. The longitudinal posterior midline skin incision was used in both groups with adequate dissection and protection of the ulnar nerve.

In the triceps tongue elevation group, tongue of the triceps was developed with the apex proximally and the base distally which was repaired at the end of fixation. In the olecranon osteotomy group, a hole was pre-drilled from the tip of the olecranon down the medullary canal using a $4.5 \mathrm{~mm}$ drill bit; then the hole was tapped to match a large $(6.5 \mathrm{~mm}) \mathrm{AO}$ cancellous screw 80 to 90 $\mathrm{mm}$ in length. Inverted ' $\mathrm{V}$ ' shaped osteotomy site was marked first over the olecranon and proximal ulna using an electro-cautery with the apex distally about $2 \mathrm{~cm}$ from the tip of olecranon. Three fourths of the olecranon was divided obliquely or in a chevron manner with a thin oscillating saw approximately $2 \mathrm{~cm}$ from its tip and rest fractured with an osteotome. In some cases, the osteotomy was fixed by the well-defined Tension band wiring method.

All the intraoperative parameters like tourniquet time, blood loss, and duration of surgery were noted. Post operatively above elbow slab was applied. A check X-ray was done on $1^{\text {st }}$ post-operative day. Postoperative complications for example: excessive soakage, postoperative distal neurovascular deficit (DNVD) and pain (VAS score) were noted. The wound was inspected on $2^{\text {nd }}$ post-operative day and the patient was discharged if wound and general condition was found satisfactory. The above elbow slab was removed and physiotherapy was started at two weeks follow up in OPD.

Then they were followed up at 6, 12 and 24 weeks with check X-rays at each visit. Range of motion, loss of reduction of fracture, clinical and radiological signs of fracture union, deformity, distal neurovascular status, time taken for functional recovery and complications were assessed. At the end of three months and six months, results were graded using the Mayo Elbow Performance Index (MEPI) as excellent, good, fair and poor for scores $>90,75-89,60-74$, and $<60$ respectively. Statistical Package for the Social Sciences (SPSS) software version 20 was used for statistical analysis and $p<0.05$ was considered statistically significant. For descriptive data- proportion, percentage, mean, standard deviation was calculated. Graphical and tabular presentation was also made. For inferential data - Chi square test for categorical data and T-test or Mann Whitney $\mathrm{U}$ test for continuous data was applied to find out the significant differences between the two groups.

\section{RESULTS}

A total of 39 cases were operated over the study period of which 17 were males and 22 were females. Most of them were in the 15-45 years age group $(n=29)$. Most of the patients were left handed (74.39\%). The mode of injury was similar between the groups. All of these variables were not statistically significant suggesting that randomization was successful (Table 1).

The timing of presentation after surgery, injury to surgery time and duration of hospital stay was not statistically significant. However, the operative time 
in the olecranon osteotomy group was found to be statistically significantly longer $(p=0.009)$, which may be due to the extra time taken for preparation and fixation of osteotomy (Table 2).

In the study, one (5\%) patient who underwent triceps tongue elevation and one (5.6\%) patient who underwent olecranon osteotomy developed iatrogenic ulnar nerve injury in the early postoperative period. Both recovered at 24 weeks follow up (Table 3).

Two patients in triceps tongue elevation group and one patient in olecranon osteotomy group had symptomatic hardware. One patient in olecranon osteotomy group had implant removed at eight months after union while the other two in triceps tongue elevation group were continued till fracture union with removal of only symptomatic cancellous screw (Table 4).

One patient (5.3\%) in olecranon osteotomy group had delayed union at the osteotomy site until 24 weeks. It was treated with bone grafting and healed six months later (Table 5).

Patients in the olecranon osteotomy group had higher MEPI score at 6,12 and 24 weeks follow up. The MEPI score in both the groups increased with time. At 24 weeks, 17 (89.47\%) patients in the olecranon osteotomy group and 11 (55\%) patients in the triceps tongue group had excellent results (Table 6).

\section{Table 1: Demographic profile of the patients}

\begin{tabular}{|c|c|c|c|c|}
\hline \multirow{2}{*}{ Parameters } & & \multicolumn{2}{|c|}{ Group } & \multirow[b]{2}{*}{ p value } \\
\hline & & $\begin{array}{l}\text { Triceps tongue elevation } \\
\qquad(n=20)\end{array}$ & $\begin{array}{l}\text { Olecranon osteotomy } \\
\qquad(n=19)\end{array}$ & \\
\hline \multirow{3}{*}{ Age distribution (years) } & $15-45$ & 13 & 16 & \multirow{3}{*}{ NA } \\
\hline & $46-75$ & 6 & 3 & \\
\hline & $76-100$ & 1 & 0 & \\
\hline Mean age (Mean $\pm S D)$ & & $42.45 \pm 20.791$ & $31.95 \pm 12.186$ & 0.062 \\
\hline \multirow{2}{*}{ Gender distribution } & Male & 9 & 8 & \multirow{2}{*}{0.855} \\
\hline & Female & 11 & 11 & \\
\hline \multirow{2}{*}{ Side involved } & Right & 4 & 6 & \multirow{2}{*}{0.323} \\
\hline & Left & 16 & 13 & \\
\hline \multirow{2}{*}{ Hand dominance } & Right & 19 & 19 & \multirow{2}{*}{ NA } \\
\hline & Left & 1 & 0 & \\
\hline \multirow{3}{*}{ Mode of injury } & Fall on level ground & 8 & 7 & \multirow{3}{*}{0.896} \\
\hline & Fall from height & 8 & 7 & \\
\hline & RTA & 4 & 5 & \\
\hline
\end{tabular}

Table 2: Distribution of different variables among two groups

\begin{tabular}{|c|c|c|c|}
\hline \multirow[b]{2}{*}{ Variables } & \multicolumn{2}{|c|}{ Group } & \multirow[b]{2}{*}{ p value } \\
\hline & $\begin{array}{l}\text { Triceps tongue elevation } \\
\qquad(n=20)(\text { Mean } \pm S D)\end{array}$ & $\begin{array}{l}\text { Olecranon osteotomy }(n=19) \\
(\text { Mean } \pm \text { SD) }\end{array}$ & \\
\hline Time of presentation after injury (hours) & $3.65 \pm 4.196$ & $2.53 \pm 2.195$ & $0.879^{* *}$ \\
\hline Injury to surgery time (days) & $5.15 \pm 5.324$ & $5.05 \pm 3.937$ & $0.687^{* *}$ \\
\hline Intraoperative Time (mins) & $96.75 \pm 9.358$ & $118.16 \pm 31.367$ & 0.009 \\
\hline Hospital stay (days) & $2.10 \pm 0.308$ & $2.63 \pm 1.862$ & $0.531^{* *}$ \\
\hline
\end{tabular}

** Mann Whitney U test

Table 3: Incidence of iatrogenic ulnar nerve injury

\begin{tabular}{|c|c|c|c|}
\hline \multirow{2}{*}{ latrogenic Ulnar Nerve injury } & \multicolumn{2}{|c|}{ Group } & \multirow{2}{*}{ p value } \\
\hline & Triceps tongue elevation [n (\%)] & Olecranon osteotomy [n (\%)] & \\
\hline Present & $1(5)$ & $1(5.6)$ & \multirow{3}{*}{0.744} \\
\hline Absent & $19(95)$ & $18(94.4)$ & \\
\hline Total & 20 & 19 & \\
\hline
\end{tabular}


Table 4: Delayed postoperative complications

\begin{tabular}{|c|c|c|c|}
\hline \multirow{2}{*}{ Symptomatic hardware } & \multicolumn{2}{|c|}{ Group } & \multirow{2}{*}{ p value } \\
\hline & Triceps tongue elevation [n (\%)] & Olecranon osteotomy [n (\%)] & \\
\hline Present & $2(11.1)$ & $1(5.26)$ & \multirow{3}{*}{0.520} \\
\hline Absent & $18(88.9)$ & $18(94.74)$ & \\
\hline Total & 20 & 19 & \\
\hline
\end{tabular}

Table 5: Analysis of clinico-radiological union at 24 weeks

\begin{tabular}{lcc}
\hline Union at $\mathbf{2 4}$ weeks & \multicolumn{1}{c}{ Group } & Olecranon osteotomy [n (\%)] \\
\hline Yes & Triceps tongue elevation [n (\%)] & $18(94.7)$ \\
No & $20(100)$ & $1(5.3)$ \\
Total & $0(0)$ & $\mathbf{1 9}$ \\
\hline
\end{tabular}

Table 6: Functional outcome by Mayo Elbow Performance score

\begin{tabular}{|c|c|c|c|}
\hline \multirow{2}{*}{ MEPI score } & & \multicolumn{2}{|c|}{ Group } \\
\hline & & Triceps tongue elevation $(n=20)$ & Olecranon osteotomy $(n=19)$ \\
\hline \multirow{4}{*}{6 weeks } & Excellent & 2 & 3 \\
\hline & Good & 8 & 8 \\
\hline & Fair & 5 & 8 \\
\hline & Poor & 5 & 0 \\
\hline \multirow{4}{*}{12 weeks } & Excellent & 7 & 9 \\
\hline & Good & 7 & 9 \\
\hline & Fair & 5 & 1 \\
\hline & Poor & 1 & 0 \\
\hline \multirow{4}{*}{24 weeks } & Excellent & 11 & 17 \\
\hline & Good & 5 & 2 \\
\hline & Fair & 4 & 0 \\
\hline & Poor & 0 & 0 \\
\hline
\end{tabular}
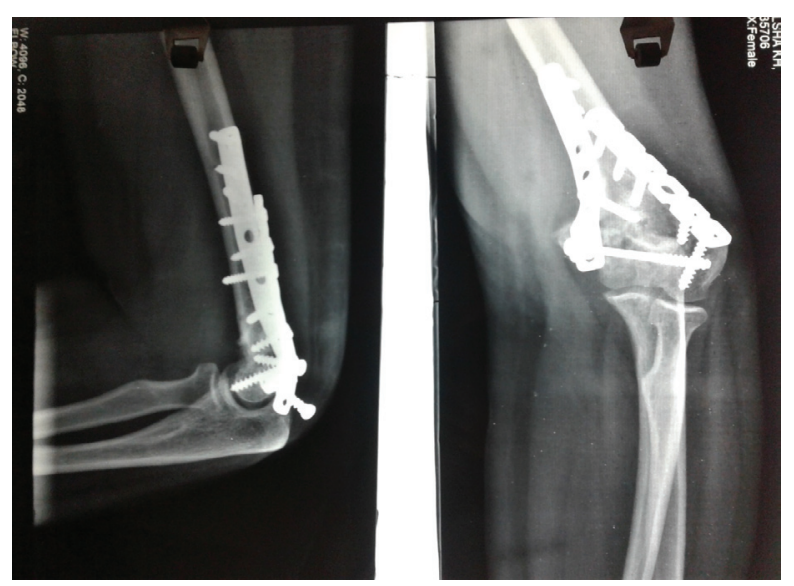

Figure 1: Symptomatic cancellous screw removed at nine months in a case of triceps tongue elevation group.

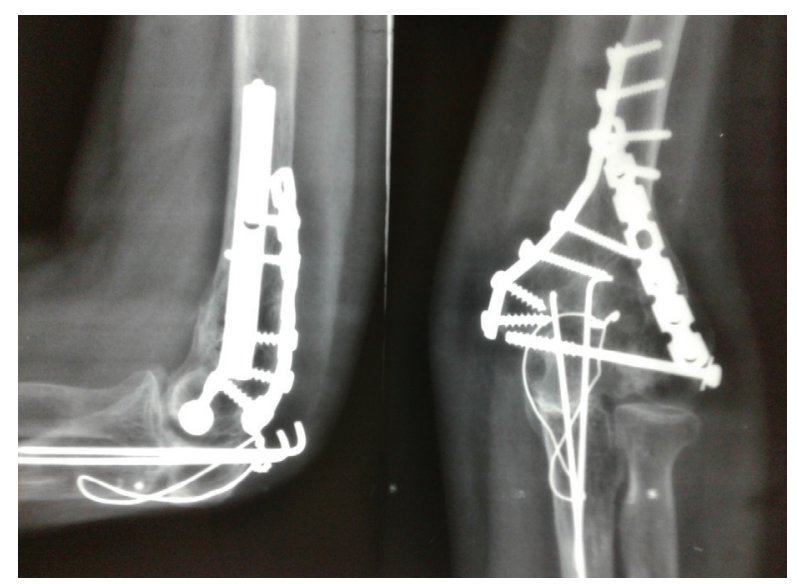

Figure 2: Delayed union of the olecranon osteotomy site at 24 weeks. 


\section{DISCUSSION}

The exposure of distal end humerus fractures - intraarticular and extra-articular is mainly done through posterior approaches. Controversy persists regarding the method of surgical approach due to the difficulty in fixation and obtaining anatomical reduction mainly in intra-articular fracture ${ }^{4,5}$. The olecranon osteotomy is considered gold standard because of the excellent exposure it offers for anatomical reduction of intraarticular fractures and it is against this approach that others are compared ${ }^{4-7}$.

The mean operative time in triceps tongue elevation group was $96.75 \pm 9.358$ minutes and in olecranon osteotomy group it was $118.16 \pm 31.367$ minutes $(p=$ 0.009), which was statistically significant. This might have been due to the extra time taken for preparation and fixation of osteotomy. However, the duration was seen to be same in study by other authors ${ }^{3}$. The interval between injury and presentation to the hospital was between one to fourteen days. In two cases, the time was 14 days due to the difficult terrain and lack of transportation facilities in our country. latrogenic ulnar nerve injury was seen in one $(5 \%)$ of triceps tongue elevation group and one $(5.6 \%)$ in olecranon osteotomy which was comparable to literature ${ }^{8-12}$. On subsequent follow up, all the patients spontaneously recovered from the ulnar nerve injury. The nerve was left in its anatomical position at the end of the surgery as advised by some authors ${ }^{13-15}$.

In our study two (11.1\%) patients in the triceps tongue elevation group and one (5.26\%) patient in the olecranon osteotomy group had symptomatic hardware which was removed at eight months after union while the other two were continued till fracture union. Similar results were reported by other authors ${ }^{16-18}$.

According to MEPI score at 24 weeks, a total of 11 (55\%) patients in the triceps tongue elevation group had excellent results and 17 (89.5\%) patients in the olecranon osteotomy group had excellent results which was similar

\section{REFERENCES}

1. Galano GJ, Ahmad CS, Levine WN. Current treatment strategies for bicolumnar distal humerus fractures. Journal of the American Academy of Orthopaedic Surgeons. 2010;18(1):20-30. [PubMed]

2. Babhulkar S, Babhulkar S. Controversies in the management of intra-articular fractures of distal humerus in adults. Indian journal of orthopaedics. 2011;45(3):216. [DOI] to the findings of other authors ${ }^{3,19,20}$. Five (25\%) patients in triceps tongue elevation group had good result and two (10.5\%) patients in the olecranon osteotomy group had good result. Four (20\%) patients in triceps tongue elevation group had fair result. None of the patients in either group had a poor result. These were comparable to previous studies in the literature ${ }^{12,18}$.

Overall, $95 \%$ of the patients had acceptable results (28 excellent, 7 good) which goes in favour of operative intervention for these kinds of fractures ${ }^{4,16,21}$.

Our study had limitations due to a smaller number of sample size and less duration of follow-up due to which the time of hardware removal due to symptomatic hardware could not be reviewed, management of the non-union could not be assessed, removal of implants after union could not be evaluated and late complications such as arthritis of the elbow joint could not be studied. Also, the note of the fracture pattern according to AO was not done and triceps power was not assessed between the groups which would have added to the value of the study.

The strength of our study was that follow-up assessment of every patient was done by the same doctor during the entire study period.

Hence, except the operative time, distal end fractures of humerus in adults had comparable results whether exposed by the triceps tongue elevation or olecranon osteotomy approach.

\section{CONCLUSION}

The surgical approaches - triceps tongue elevation and olecranon osteotomy were identical in terms of union, post-operative function and rate of complications. There was increased intraoperative time in the olecranon osteotomy approach suggesting that patient who cannot tolerate longer intraoperative time may benefit from triceps tongue elevation approach.

3. Gupta G, Ghosh S, Chaudhuri A, Datta S, Dutta S, Dugar N. Comparative study of different approaches for open reduction and internal fixation in fractures of distal humerus. Saudi Journal of Sports Medicine. 2015;15(1):68. [DOI]

4. Jupiter JB, NeffU, Holzach P,AllgöwerM.Intercondylar fractures of the humerus - An operative approach. The Journal of Bone \& Joint Surgery. 1985;67(2):22639. [DOI] 
5. Müller ME, Allgöwer M, Perren S. Manual of internal fixation: techniques recommended by the AO-ASIF group: Springer Science \& Business Media; 1991. [DOI]

6. Wilkinson JM, Stanley D. Posterior surgical approaches to the elbow: a comparative anatomic study. Journal of shoulder and elbow surgery. 2001;10(4):380-2. [DOI]

7. Zagorski JB, Jennings JJ, Burkhalter WE, Uribe JW. Comminutedlntraarticular Fractures of the Distal Humeral Condyles: Surgical vs. Nonsurgical Treatment. Clinical orthopaedics and related research. 1986;202:197-204. [PubMed]

8. Södergård J, Sandelin J, Böstman O. Postoperative complications of distal humeral fractures: 27/96 adults followed up for 6 (2-10) years. ActaorthopaedicaScandinavica. 1992;63(1):85-9. [PubMed]

9. Kundel K, Braun W, Wieberneit J, Rüter A. Intraarticular Distal Humerus Fractures: Factors Affecting Functional Outcome. Clinical orthopaedics and related research. 1996;332:200-8.[DOI]

10. Kinik $H$, Atalar $H$, Mergen E. Management of distal humerus fractures in adults. Archives of orthopaedic and trauma surgery. 1999;119(7-8):4679. [DOI]

11. Allende C, Allende B, Allende B, Bitar I, Gonzalez G. Intercondylar distal humerus fractures-surgical treatment and results. Chirurgie de la main. 2004;23(2):85-95. [PubMed]

12. Chen G, Liao Q, Luo W, Li K, Zhao Y, Zhong D. Triceps-sparing versus olecranon osteotomy for ORIF: analysis of 67 cases of intercondylar fractures of the distal humerus. Injury. 2011;42(4):366-70. [DOI]
13. Jupiter JB. The management of nonunion and malunion of the distal humerus-a 30-year experience. Journal of orthopaedic trauma. 2008;22(10):742-50. [DOI]

14. Chen RC, Harris DJ, Leduc S, BorrelliJr JJ, Tornetta III $P$, Ricci WM. Is ulnar nerve transposition beneficial during open reduction internal fixation of distal humerus fractures? Journal of orthopaedic trauma. 2010;24(7):391-4. [DOI]

15. Vazquez O, Rutgers $M$, Ring DC, Walsh $M$, Egol KA. Fate of the ulnar nerve after operative fixation of distal humerus fractures. Journal of orthopaedic trauma. 2010;24(7):395. [DOI]

16. Henley MB. Intra-articular distal humeral fractures in adults. The Orthopedic clinics of North America. 1987;18(1):11.[PubMed]

17. Mckee MD, Wilson TL, Winston L, Schemitsch EH, Richards RR. Functional outcome following surgical treatment of intra-articular distal humeral fractures through a posterior approach. J Bone Joint Surg Am. 2000; 82(12):1701. [DOI]

18. Coles CP, Barei DP, Nork SE, Taitsman LA, Hanel DP, Henley MB. The olecranon osteotomy: a six-year experience in the treatment of intraarticular fractures of the distal humerus. Journal of orthopaedic trauma. 2006; 20(3):163-70. [DOI]

19. Wang AA, Mara $M$, Hutchinson DT. The proximal ulna: an anatomic study with relevance to olecranon osteotomy and fracture fixation. Journal of shoulder and elbow surgery. 2003; 12(3):293-6. [DOI]

20. Marsh M, Patel N, Limb D. A safe technique for olecranon osteotomy. The Annals of The Royal College of Surgeons of England. 2010; 92(6):532-3. [DOI]

21. Sanders RA, Raney EM, Pipkin SP. Operative treatment of bicondylar intraarticular fractures of the distal humerus. Orthopedics. 1992;15(2):159-63. [PubMed] 